\title{
Optimizing Neuro-Fuzzy Fault Diagnostic Algorithm for Photovoltaic Systems
}

\author{
A.H. Mohamed ${ }^{1}$ and K.H. Marzouk ${ }^{1}$ \\ ${ }^{1}$ Solid State and Electronic Accelerators Dept., National Centre for Radiation Research and Technology \\ (NCRRT), Atomic Energy Authority.
}

\begin{abstract}
The main goal of this research is to develop a novel optimum neuro-fuzzy system for diagnosis the complex and dynamic systems. It has used the Particle Swarm Optimization (PSO) technique for training the Adaptive Neuro Fuzzy Inference System (ANFIS) off-line. The proposed system has applied for diagnosis the faults of two complex Photovoltaic (PV) systems. They are used to feed the power for lighting and pumps in a synchrotron building inside a radiation centre and the power for a house in a rural village. Its achieved results are compared with three ANFIS' diagnostic systems. They are: traditional neuro-fuzzy diagnostic systems, optimized ANFIS with genetic algorithm, optimized ANFIS with gradient descendent technique. The suggested system has proved its good performance to be applied for diagnose the complex dynamic systems.
\end{abstract}

Keywords: Fault diagnosis, neuro-fuzzy system, Practice Swarm Optimization (PSO), Optimization, and PV systems.

\section{Introduction}

For several years ago, Photovoltaic (PV) systems are represented as one of the main renewable energy resources that expected to play important role in solving the power problems all over the world. PV systems are used to replace or share the traditional power sources due to sources due to: (1) friendless of the solar energy for the environment. (2) difficulties and high cost to feed the traditional power for far rural areas. (3) clear shortage appeared recently in the traditional power sources [1].

Generally, a PV (or solar cell) system consists of solar cell module, converter and batteries. The PV module that consists of many solar cells connected in series and PV modules are wired together into array both in series and in parallel to provide the necessary power (voltage or currents) [2]. Each solar cell is a semiconductor photovoltaic diode which converts solar radiation into electric current by the photovoltaic effect, which is a physical and chemical phenomenon [3].

Solar photovoltaic cell is modeled by current voltage (I-V) characterization. It is a non-linear relationship due to the semiconductor behavior of the cell. However, the output power of a PV array (sometimes called solar panels) changes considerably. The reasons behind these changes are the variation of the soiling, non uniform irradiation, cloud, time of day, locations, partially shading, etc [4].

However, fault diagnosis of such systems is very complexity, unmanaging and time consuming task. It is found that, integrating the fuzzy logic and neural network-based algorithms in the neuro-fuzzy systems have improved the performance of the diagnostic systems under varying input conditions.

But, the neuro-fuzzy systems have some main limitations due to the needs of the NN module for great number of training examples to ensure high accuracy of the system [5]. The performance of the NN's depends on their weights those are mainly based on the structure and the training examples. However, researchers have suggested optimizing the training' parameters for the fuzzy system using optimization techniques. On the other hand, traditional optimization method suffers from complexity when dealing with diagnosis of systems those having a great number of variables.

Therefore, the present research introduces a novel algorithm that can incorporate the particle swarm artificial intelligence optimization technique to optimize the training process of the fuzzy module. Therefore, the suggested system can enhance the performance of the neuro-fuzzy diagnostic systems.

The reminder of this paper is organized as follows. Section 2 discusses the adaptive neuro-fuzzy interface systems. Section 3 deals with particle Swarm optimization techniques. Section 4 explains the related work. While, Section 5 discusses the proposed system. Section 6 presents the applicability of the proposed system for diagnosis two complex photovoltaic systems and its evaluated results. Section 7 concludes the work.

\section{Adaptive Neuro-Fuzzy Inference Systems}

Adaptive neuro-fuzzy inference system (ANFIS) is considered the core neuro-fuzzy model that can adapt itself through the training process. It is a hybrid model which combines the neural networks (NNs) adaptive capability and the fuzzy logic (FL) approach. An adaptive network is a multi-layers feed forward network in which each node (neuron) performs a particular function on the inputs [6]. ANFIS architecture can 
identify optimal membership functions of the fuzzy logic for achieving the desired input-output mappings using the neural networks. Figure (1) represents the block diagram of the neuro-fuzzy system. The neural network applies the least square and the back propagation methods for training the fuzzy inference system (FIS) membership function' parameters. This can decrease the number of the training data set. The system converges when the training cycles or the checking errors are within the acceptable values [7].

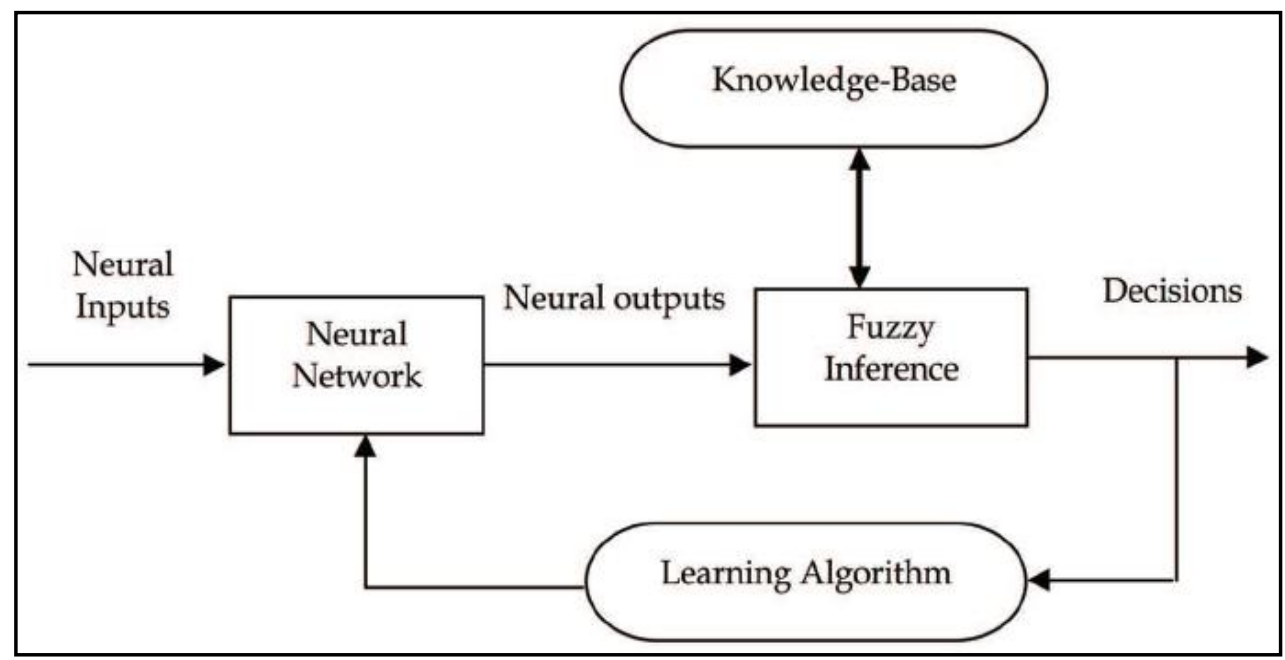

Fig. (1): Block diagram of Neuro-Fuzzy System.

Takagi-Sugeno-Kang model (TSK model) is represented as the standard style fuzzy inference system based on sub-clustering on the data. A typical fuzzy rule using the first-order TSK model has the form:

If $x_{1}$ is $A_{i 1}$ AND...AND $x_{m}$ is $A_{i m}$ then $y_{i}$ is $f_{i}\left(x_{1}, \ldots, x_{m}\right)(1)$

where $\mathrm{x}_{1}, \ldots ., \mathrm{x}_{\mathrm{m}}$ are input variables to the neuro-fuzzy inference system ( $\mathrm{m}$ is the number of input variables), $A_{i 1}, \ldots ., A_{i m}$ are antecedent membership function of each input variable for the $i^{\text {th }}$ rule $(i=1,2, ., n)$ and $y_{i}$ is the output of the $\mathrm{i}^{\text {th }}$ rule. The estimated output for the fuzzy system is described by

$$
\widehat{y}=\sum_{i=1}^{n} \bar{w}_{i} f_{i}
$$

\section{where}

$$
\bar{w}_{i}=\frac{w_{i}}{\sum_{i=1}^{n} w_{i}}
$$

and

$$
w_{i}=\prod_{j=1}^{m} A_{i j}\left(x_{i}\right)
$$

The input values to the fuzzy inference system are $x_{1}, x_{2}, \ldots, x_{m}$, and $A_{i j}$ means the membership function of the $j^{\text {th }}$ rule [8]. 


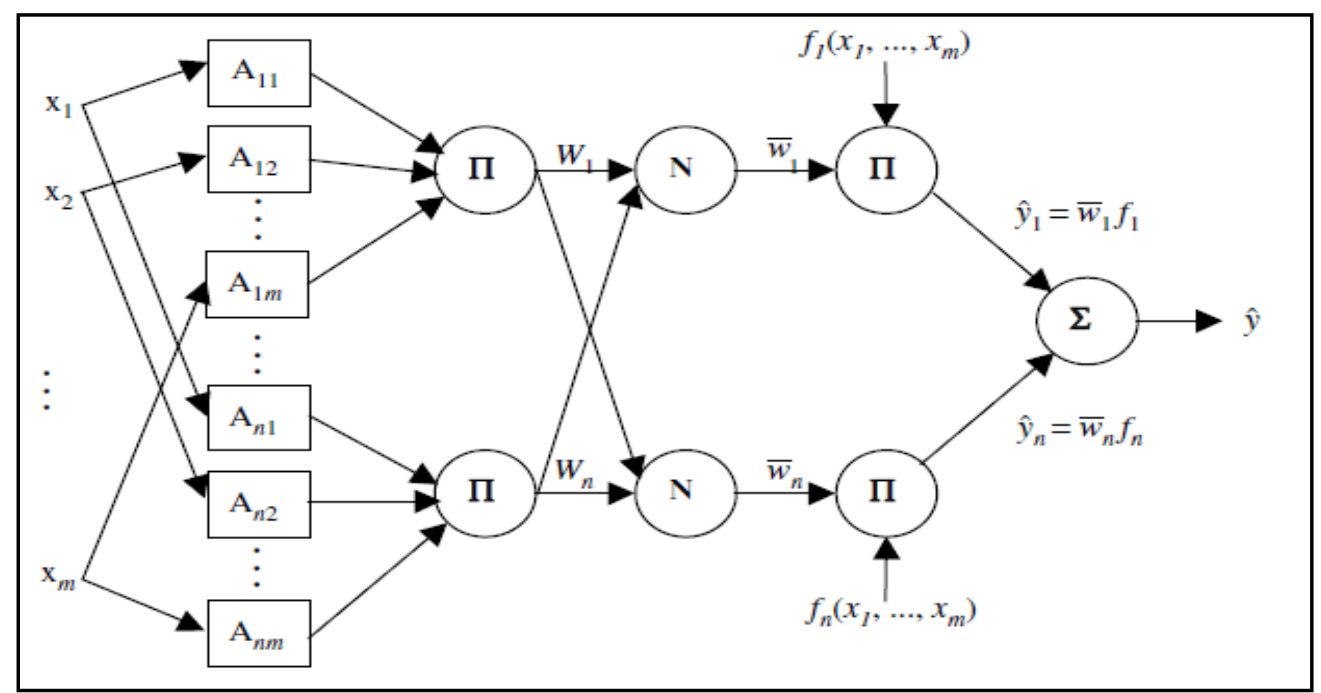

Fig. (2): Structure of Adaptive Neuro-fuzzy inference system (ANFIS).

\section{Particle Swarm Optimization Technique}

Particle Swarm Optimization (PSO) was introduced by James Kennedy and Russell C Eberhart in the year 1995. PSO is a stochastic and a population-based optimization technique. It is inspired by social behavior metaphor of bird flocking or fish schooling.

The PSO algorithm uses a swarm of individuals (called particles). Each particle represents a candidate solution [9]. The particle simulates the success of its neighboring particles and its own determined successes. Therefore, the position of a particle is affected by the best particle in a neighborhood $P$ best or the best solution achieved by all the particles in the entire population Gbest. However, the particle position $x i$ is changed based on the following formula:

$$
x_{\mathrm{i}}^{\mathrm{k}+1}=x_{\mathrm{i}}^{\mathrm{k}}+\Phi_{\mathrm{i}}^{\mathrm{k}+1}
$$

Where the velocity component $\Phi i$ represents the step size [10]. PSO technique shares the evolutionary techniques in many similar properties. But, it differences about others such as genetic algorithms (GAs) in other properties. For example, PSO has no evolution operators such as crossover and mutation like GA [11].

PSO algorithm starts with a population of random candidates' solutions, conceptualized as particles. Each particle can move a random velocity and moves through the problem space. It is moved towards the location of the best fitness particle so far across the whole population (global version of the algorithm) [12].

\section{Related Work}

Several systems have used the ANFIS and other techniques for PV cell fault detecting and diagnostic techniques, as: Traditional approaches based on power losses have been proposed for detecting the faults [13]. While, a decision tree model and time domain reflectometry (TDR) were used for detecting the faults of PV systems. More recently, intelligent systems based on neural network, fuzzy systems or neuro-fuzzy networks for detecting the faults in PV fields were introduced [14]. Besides, signal processing is represented another approach that is used to detect online faults in PV systems [15].

But, these previous techniques suffer from some limitations as: (1) the traditional and decision tree methods were concerning only on the detection of the faults $[16,17]$. Also, the previous works of the intelligent systems did not develop a complete algorithm for faults detection and diagnosis the real system effectively. Besides, these diagnostic systems are operated off-line and have not introduced repairing methods [18].

\section{The Proposed System}

Nowadays, neuro-fuzzy diagnostic systems have a great wide spreading to automate the fault diagnosis of the modern complex systems in all the engineering fields.

But, traditional ANFIS systems still suffer from some problems. They face complexity, time losses and sometimes inefficient accurate output. Besides, these systems have used the conventional optimization algorithm such as the back propagation to train and adapt the values of the parameters' optimization. Back propagation and other conventional optimization algorithms have a main limitation due to its easily sticking at 
local optima. To overcome these challenges, the proposed system suggests a new optimum fuzzy-neural network diagnostic algorithm. It uses the particle swarm optimization technique to optimize the Adaptive Neural-based Fuzzy Inference System (ANFIS). It can train the antecedent parameters of a fuzzy inference system. Besides, it can completely automate the diagnostic process.

The proposed system has used Mamdani's fuzzy logic controller (FLC). It applies the asymmetric triangular membership function distributions to map inputs and the output those represented the symptoms of the failure and its corresponding diagnosis respectively. Inputs and output are arbitrarily assigned class labels 'mild ('m')', 'moderate ('M')', and 'severe ('s')' with some numeric range. Four symptoms are represented as 'mild'(m), 'moderate'(M) and 'severe' (s) with overlapping scales such as mild-to-moderate (mM), moderateto-severe (Ms) and 'very severe' (s) as shown in fig. (2). These overlapping regions are mainly focus by the fuzzy-neural model that aims to differentiate it into 'mild', 'moderate' and 'severe'.

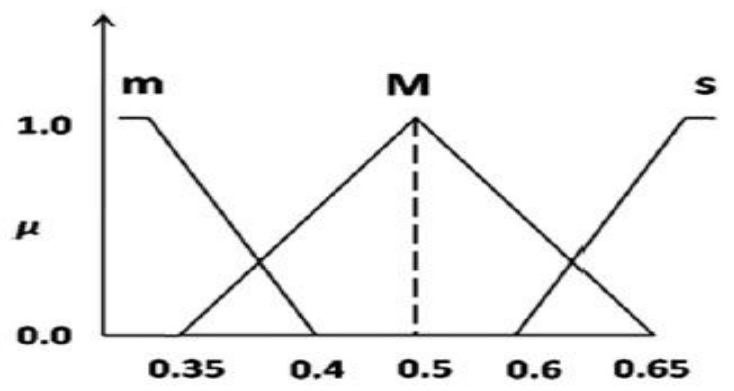

Fig. (2): Triangular membership function distribution of symptoms (inputs) and the grades of failure (output).

The proposed fuzzy system has eight inputs, each with two possibilities one time. Hence, there are a total of $2^{4}$ i.e., 16 rules that might fire among $3^{4}$, i.e., 81 possible rules. These inputs are: temperature $\left({ }^{\circ} \mathrm{C}\right)$, lightness, steam flow and irradiance.

The operation of the proposed system is started by training the fuzzy logic module by the particle swarm optimization technique as shown in fig. (3). The training process has two steps:

1- The inputs are propagated to the output. Then, the neural network is used to estimate the optimal consequent parameters while the antecedent parameters (membership functions) are assumed to be fixed in the current cycle.

2- The inputs are propagated again and the particle swarm optimization is used to modify the antecedent parameters, while the consequent parameters remain fixed.

3- Steps $1 \& 2$ are repeated and iterated till the desired output error is reduced or till a maximum number of training cycles is reached.

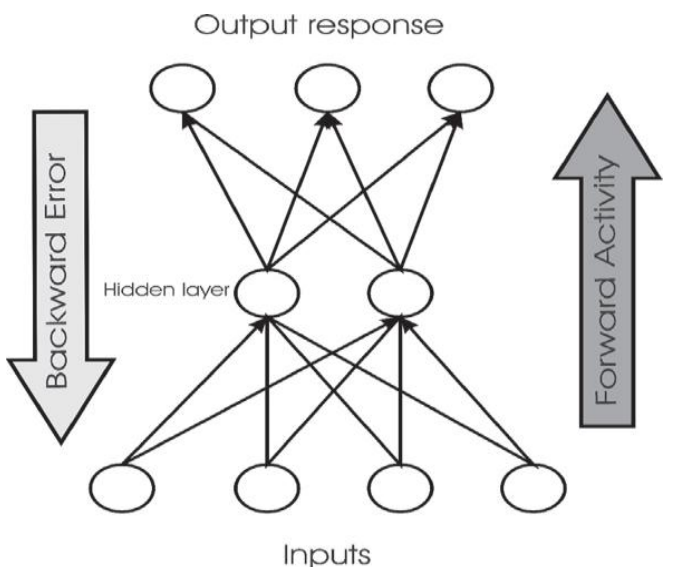

Fig. (3): Training Process for ANFIS by PSO Technique

The fuzzy module is trained (offline) with 230 real cases of failures. For one training case, there are four inputs (symptoms) each having three Grades of failures (GF). For an input, maximum two GFs can take part and hence two membership values (l) could be computed. After the training process is completed, the proposed system has tested the optimized rule set by 103 cases. Figure (4): represents the flow chart of the training process of the proposed system by the particle swarm optimization.

ANFIS is implemented in the MATLAB \& Simulink that allows for generation of TSK. After the fuzzy system has executed their main tasks, the proposed system has applied the Centre of Area (COA) method for 
defuzzification process. To test the performance of the proposed neuro-fuzzy model, it has run for 88 cases with the optimized rule set.

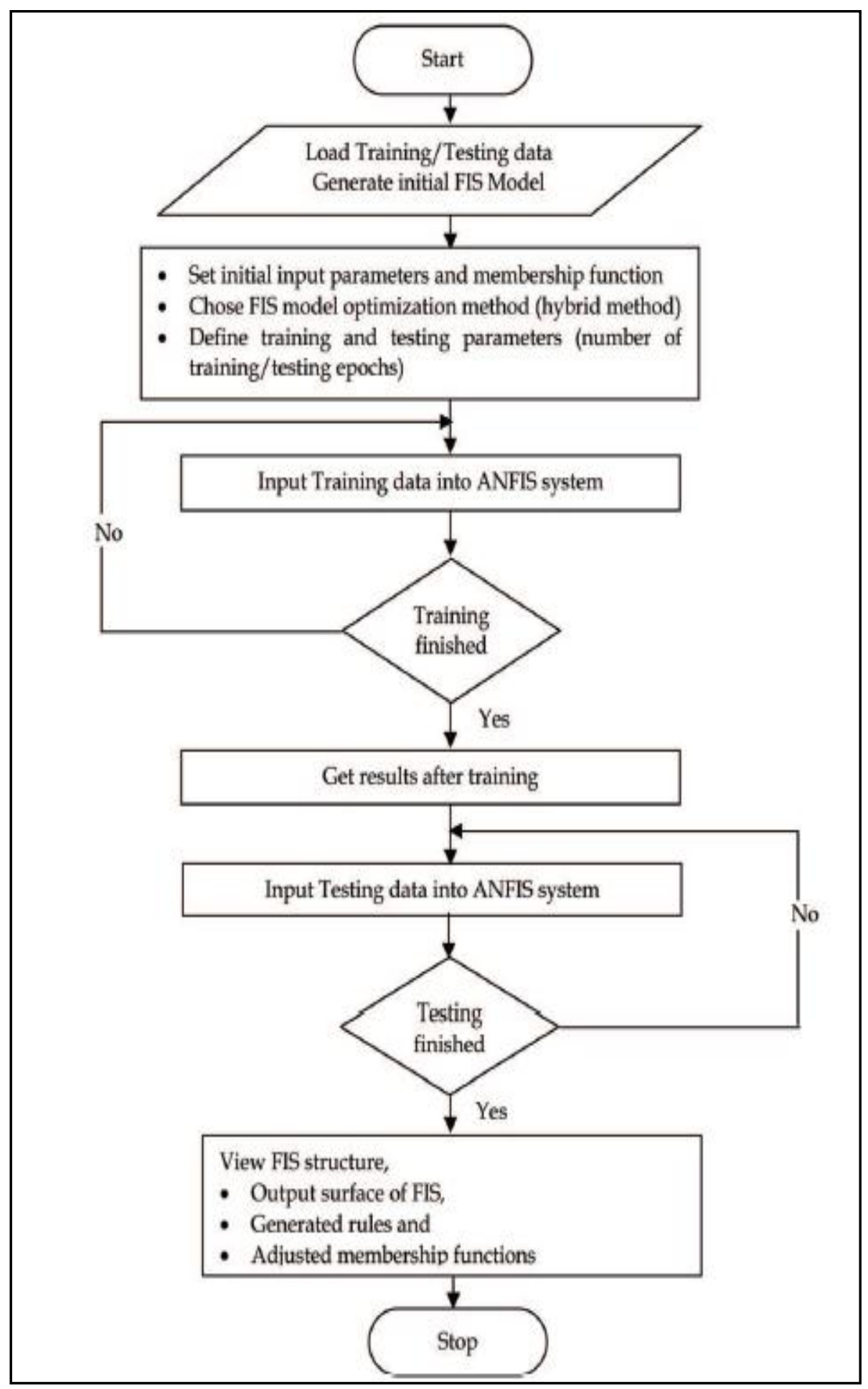

Fig. (4): Flowchart of the proposed training process by the PSO.

\section{Applicability of the Proposed System}

The proposed system introduces a novel optimized neuro-fuzzy algorithm that can solve the diagnostic problems of many different types of complex systems. To evaluate the performance of the proposed system for the present case of study, it has applied for diagnosis the faults of a complex photovoltaic system that is used for feeding the power to lighting pumps used in a synchrotron building inside a radiation centre and feeding the required power for a house in a rural village. The present case of the tested PV system consists of solar 
photovoltaic modules of $500 \mathrm{~kW}$ PV system and a grid connected converter of $500 \mathrm{~kW}$ capacity with batteries storage. The system is designed to have a life time of 30 years so the PV panels will not be replaced.

Results are compared to that achieved by a traditional ANFIS based diagnostic systems [19], optimized ANFIS gradient descendent (GD) [20] and an optimized ANFIS with genetic algorithm (GA) system for training the fuzzy module [21]. Table $(1 \& 2)$ represent these comparisons.

Table (1): A comparison between the simulated results obtained from a traditional ANFIS system, Optimized ANFIS with gradient descendent, Optimized ANFIS with GA and the proposed system for a synchrotron building

\begin{tabular}{|c|c|c|c|c|c|c|c|c|c|c|}
\hline \multicolumn{11}{|c|}{ Case 1: Feeding the power for lighting and pumps in a Synchrotron Building } \\
\hline \multicolumn{3}{|c|}{ Environment Conditions } & \multicolumn{8}{|c|}{ Simulation Results } \\
\hline \multirow[t]{2}{*}{$\begin{array}{l}\text { Type of } \\
\text { faults }\end{array}$} & \multirow[t]{2}{*}{$\begin{array}{l}\text { Temp. } \\
{ }^{\circ} \mathbf{C}\end{array}$} & \multirow[t]{2}{*}{\begin{tabular}{|l|} 
Irradi \\
a-tion \\
$\left(\mathbf{W} / \mathbf{m}^{2}\right)$
\end{tabular}} & \multicolumn{2}{|c|}{$\begin{array}{l}\text { traditional ANFIS } \\
\text { system }\end{array}$} & \multicolumn{2}{|c|}{$\begin{array}{l}\text { Optimized ANFIS } \\
\text { with GD system }\end{array}$} & \multicolumn{2}{|c|}{$\begin{array}{c}\text { Optimized ANFIS } \\
\text { with GA system }\end{array}$} & \multicolumn{2}{|c|}{$\begin{array}{c}\text { Proposed optimized } \\
\text { ANFIS with PSO } \\
\text { System }\end{array}$} \\
\hline & & & $\begin{array}{c}\text { Accuracy } \\
(\%)\end{array}$ & $\begin{array}{l}\text { Time } \\
\text { (sec.) }\end{array}$ & $\begin{array}{c}\text { Accuracy } \\
(\%)\end{array}$ & $\begin{array}{c}\text { Time } \\
\text { (sec.) }\end{array}$ & $\begin{array}{c}\text { Accuracy } \\
(\%)\end{array}$ & $\begin{array}{l}\text { Time } \\
\text { (sec.) }\end{array}$ & $\begin{array}{c}\text { Accuracy } \\
(\%)\end{array}$ & $\begin{array}{l}\text { Time } \\
\text { (sec.) }\end{array}$ \\
\hline \multirow{3}{*}{ Normal } & 30 & 320 & 93.0 & 10.4 & 94.2 & 8.8 & 95.1 & 7.7 & 97.6 & 4.2 \\
\hline & 32 & 490 & 92.4 & 10.5 & 94.7 & 8.7 & 95.5 & 7.5 & 97.7 & 4.3 \\
\hline & 34 & 530 & 92.8 & 10.3 & 93.8 & 8.6 & 95.4 & 7.6 & 97.3 & 4.2 \\
\hline \multirow{3}{*}{$\begin{array}{l}\text { Short- } \\
\text { Circuit }\end{array}$} & 30 & 320 & 92.6 & 10.2 & 93.9 & 8.6 & 95.3 & 7.4 & 96.1 & 4.1 \\
\hline & 32 & 490 & 93.3 & 10.0 & 93.1 & 8.3 & 95.0 & 7.3 & 96.3 & 4.3 \\
\hline & 34 & 530 & 93.8 & 9.9 & 93.7 & 8.0 & 95.2 & 7.5 & 96.7 & 4.0 \\
\hline \multirow{3}{*}{$\begin{array}{l}\text { Open- } \\
\text { Circuit }\end{array}$} & 30 & 320 & 93.2 & 9.8 & 93.5 & 8.1 & 94.7 & 7.8 & 97.5 & 5.2 \\
\hline & 32 & 490 & 93.4 & 9.7 & 93.6 & 7.9 & 94.5 & 7.1 & 97.3 & 5.6 \\
\hline & 34 & $\mathbf{5 3 0}$ & 93.4 & 9.7 & 93.6 & 7.9 & 94.5 & 7.1 & 97.3 & 5.6 \\
\hline \multirow{3}{*}{$\begin{array}{c}\text { Degrad } \\
\text { ation }\end{array}$} & 30 & 320 & 93.8 & 9.6 & 94.1 & 10.7 & 94.3 & 7.7 & 97.5 & 5.8 \\
\hline & 32 & 490 & 93.9 & 9.3 & 94.3 & 10.5 & 94.2 & 8.0 & 97.6 & 5.9 \\
\hline & 34 & $\mathbf{5 3 0}$ & 93.9 & \begin{tabular}{|l|l}
9.3 \\
\end{tabular} & 94.3 & 10.5 & 94.2 & 8.0 & 97.6 & 5.9 \\
\hline \multirow[t]{3}{*}{ Shading } & 30 & 320 & 94.1 & 8.9 & 94.0 & 11.6 & 94.3 & 8.2 & 97.3 & 5.1 \\
\hline & 32 & 490 & 94.3 & 8.7 & 94.2 & 11.3 & 93.9 & 8.4 & 97.8 & 4.9 \\
\hline & 34 & $\mathbf{5 3 0}$ & 94.3 & \begin{tabular}{|l|l|}
8.7 \\
\end{tabular} & 94.2 & 11.3 & 93.9 & 8.4 & 97.8 & 4.9 \\
\hline \multirow{3}{*}{$\begin{array}{l}\text { Charging } \\
\text { Module }\end{array}$} & 30 & 320 & 94.2 & 9.2 & 94.8 & 9.5 & 93.7 & 8.8 & 98.2 & 4.7 \\
\hline & 32 & 490 & 94.6 & 9.5 & 94.4 & 9.7 & $\begin{array}{l}93.8 \\
\end{array}$ & 8.4 & 97.9 & 3.6 \\
\hline & 34 & $\mathbf{5 3 0}$ & 94.6 & \begin{tabular}{|c|}
9.5 \\
\end{tabular} & 94.4 & 9.7 & \begin{tabular}{|l|}
93.8 \\
\end{tabular} & 8.4 & 97.9 & 3.6 \\
\hline \multirow{3}{*}{$\begin{array}{l}\text { Battery } \\
\text { Module }\end{array}$} & 30 & 320 & 94.5 & 8.8 & 93.8 & 10.8 & 94.0 & 8.0 & 98.6 & 4.3 \\
\hline & 32 & 490 & 94.2 & 8.5 & 94.1 & 10.5 & 94.3 & 8.5 & 98.5 & 4.5 \\
\hline & 34 & 530 & 94.2 & 8.5 & 94.1 & 10.5 & 94.3 & 8.5 & 98.5 & 4.5 \\
\hline
\end{tabular}

Table (2): A comparison between the simulated results obtained from a traditional ANFIS system, Optimized ANFIS with gradient descendent, Optimized ANFIS with GA and the proposed system for a house in a rural village.

\begin{tabular}{|c|c|c|c|c|c|c|c|c|c|c|}
\hline \multicolumn{11}{|c|}{ Case 2: Feeding the Power for a House in a Rural Village } \\
\hline \multicolumn{3}{|c|}{ Environment Conditions } & \multicolumn{8}{|c|}{ Simulation Results } \\
\hline \multirow[t]{2}{*}{$\begin{array}{l}\text { Type of } \\
\text { faults }\end{array}$} & \multirow[t]{2}{*}{$\begin{array}{l}\text { Temp. } \\
{ }^{\circ} \mathbf{C}\end{array}$} & \multirow[t]{2}{*}{$\begin{array}{l}\text { Irradi- } \\
\text { ation } \\
\left(\mathbf{W} / \mathbf{m}^{2}\right)\end{array}$} & \multicolumn{2}{|c|}{$\begin{array}{l}\text { traditional ANFIS } \\
\text { system }\end{array}$} & \multicolumn{2}{|c|}{$\begin{array}{l}\text { Optimized ANFIS } \\
\text { with GD system }\end{array}$} & \multicolumn{2}{|c|}{$\begin{array}{l}\text { Optimized ANFIS } \\
\text { with GA system }\end{array}$} & \multicolumn{2}{|c|}{$\begin{array}{l}\text { Proposed optimized } \\
\text { ANFIS with PSO } \\
\text { System }\end{array}$} \\
\hline & & & Accuracy & $\begin{array}{l}\text { Time } \\
\text { (sec.) }\end{array}$ & Accuracy & \begin{tabular}{|c|} 
Time \\
(sec.) \\
\end{tabular} & Accuracy & $\begin{array}{l}\text { Time } \\
\text { (sec.) }\end{array}$ & $\begin{array}{l}\text { Accurac } \\
\text { y }\end{array}$ & $\begin{array}{l}\text { Time } \\
\text { (sec.) }\end{array}$ \\
\hline \multirow{3}{*}{ Normal } & 26 & 300 & 90.0 & 9.4 & 92.3 & 7.8 & 93.2 & 6.2 & 97.0 & 3.6 \\
\hline & 28 & 450 & 90.5 & 9.5 & 92.7 & 7.4 & 93.4 & 6.5 & 97.7 & 3.3 \\
\hline & 30 & 500 & 91.8 & 9.3 & 92.6 & 7.6 & 93.5 & 6.6 & 97.3 & 3.5 \\
\hline \multirow{3}{*}{$\begin{array}{l}\text { Short- } \\
\text { Circuit }\end{array}$} & 26 & 300 & 91.2 & 9.6 & 93.5 & 7.6 & 94.1 & 6.9 & 96.1 & 3.7 \\
\hline & 28 & 450 & 92.3 & 9.7 & 93.3 & 7.9 & 94.6 & 7.0 & 96.3 & 3.3 \\
\hline & 30 & 500 & 92.4 & 10.0 & 94.0 & 8.0 & 94.8 & 7.2 & 96.7 & 3.0 \\
\hline \multirow{3}{*}{$\begin{array}{l}\text { Open- } \\
\text { Circuit }\end{array}$} & 26 & 300 & 92.6 & 10.2 & 93.8 & 8.3 & 94.9 & 7.5 & 97.5 & 2.8 \\
\hline & 28 & 450 & 92.4 & 9.8 & 93.6 & 8.5 & 94.7 & 7.3 & 97.3 & 3.0 \\
\hline & 30 & 500 & 92.0 & 9.7 & 93.7 & 8.7 & 94.6 & 7.1 & 97.0 & 3.6 \\
\hline \multirow{2}{*}{$\begin{array}{c}\text { Degrad } \\
\text { ation }\end{array}$} & 26 & 300 & 93.8 & 9.2 & 93.9 & 8.9 & 93.8 & 7.4 & 97.2 & 3.7 \\
\hline & 28 & 450 & 93.7 & 8.9 & 94.1 & 8.5 & 93.9 & 7.8 & 96.8 & 4.1 \\
\hline
\end{tabular}


Optimizing Neuro-Fuzzy Fault Diagnostic Algorithm for Photovoltaic Systems

\begin{tabular}{|c|c|c|c|c|c|c|c|c|c|c|}
\hline & 30 & 500 & 94.2 & 9.1 & 94.3 & 9.2 & 93.8 & 7.9 & 96.9 & 4.3 \\
\hline \multirow[t]{3}{*}{ Shading } & 26 & 300 & 94.5 & 8.9 & 94.2 & 9.4 & 94.1 & 8.1 & 96.5 & 4.5 \\
\hline & 28 & 450 & 94.3 & 8.7 & 94.7 & 10.3 & 94.3 & 8.3 & 97.3 & 4.7 \\
\hline & 30 & 500 & 94.6 & 8.6 & 94.8 & 10.2 & 94.5 & 8.4 & 97.2 & 4.5 \\
\hline \multirow{3}{*}{$\begin{array}{l}\text { Charging } \\
\text { Module }\end{array}$} & 26 & 300 & 94.2 & 8.9 & 95.0 & 10.5 & 94.7 & 8.7 & 96.8 & 4.3 \\
\hline & 28 & 450 & 94.8 & 9.2 & 95.2 & 9.8 & 94.8 & 8.7 & 96.5 & 4.2 \\
\hline & 30 & 500 & 95.1 & 9.3 & 95.4 & 9.7 & 94.6 & 8.8 & 97.3 & 4.0 \\
\hline \multirow{3}{*}{$\begin{array}{l}\text { Battery } \\
\text { Module }\end{array}$} & 26 & 300 & 94.7 & 9.1 & 94.8 & 10.1 & 95.1 & 8.9 & 97.5 & 4.1 \\
\hline & 28 & 450 & 94.2 & 9.2 & 94.6 & 10.3 & 95.4 & 9.1 & 97.8 & 4.3 \\
\hline & 30 & 500 & 94.5 & 9.5 & 94.1 & 10.5 & 95.3 & 9.2 & 98.0 & 4.5 \\
\hline
\end{tabular}

From the results of the comparison between the proposed system and the other three algorithms, it is found that that the proposed system can improve the performance of the ANFIS' systems by optimizing the parameters of its fuzzy module. Also, the proposed system proves its efficiency when compared with the three other traditional ANFIS and optimized ANFIS with gradient descendent, ANFIS with genetic algorithms. Thus, the proposed system can increase the accuracy of the ANFIS diagnostic system and decrease the required time for this operation.

It is found that, the proposed system has a significant higher accuracy rather the traditional and gradient descendent optimized ANFIS system. While, it has a clear decreasing in the diagnostic process time rather than all the three tested ANFIS' systems. Although the optimized ANFIS with GA has more accuracy rather than the traditional and the gradient descendent, GA suffers from longer processing time. Therefore, the proposed system has improved the performance of the ANFIS' systems by decreasing its processing time and complexity. While, increasing their accuracy and reliability. So, the suggested system has a good acceptance performance to be applied for diagnosing the complex and dynamic behavior systems.

\section{Conclusions}

This research aims to develop a new optimized ANFIS neuro-fuzzy algorithm used for photovoltaic systems. The proposed system can have the goodness of both the neural network and the fuzzy systems. Besides, it can use the practice swarm optimization (PSO) technique to optimize the storage size and the amount of training data for the fuzzy system. This can improve the performance of the diagnostic systems for the dynamic systems.

Suggested system has been applied for diagnosis the failures of two PV systems used for feeding the power for a synchrotron building in a radiation centre and a house in the rural village. Its achieved results are compared with those gotten from the traditional ANFIS and those optimized with the gradient descendent and the genetic algorithm. Suggested system has decreased the diagnostic time and complexity. Besides, it has increased the accuracy and reliability of the ANFIS' systems. Proposed system has proved its success for applying in the real-time situations.

\section{References}

[1] Y. Riffonneau, S. Bacha, F. Barruel, and S. Ploix, (July 2011), "Optimal Power Flow Management for Grid Connected PV Systems With Batteries “, IEEE Transactions on Sustainable Energy, Vol. 2, No. 3, pp.309-320.

[2] P. Romano, R. Candela, M. Cardinale, Vi. Li Vigni, D. Musso, and E. R. Sanseverino, "Optimization of Photovoltaic Energy Production through an Efficient Switching Matrix“, (2013), Journal of Sustainable Development of Energy, Water and Environment Systems, Vol. (1), Issue (3), pp. 227-236.

[3] Wilson, P., Storey, J., and Bagnall, D., (2012), Improved Optimization Strategy for Irradiance Equalization in Dynamic Photovoltaic Arrays, IEEE Transactions on Power Electronics, vol. 28, no. 6, pp. 2946-2956.

[4] K. Ishaque and Z. Salam, (2011), 'An improved modeling method to determine the model parameters of photovoltaic (PV) modules using differential evolution (DE),' Solar Energy, Vol. 85, pp. 2349-2359.

[5] S. T. BRASSAI, S. HAJDU and T. TĂMAS, (2015), " Embedded Adaptive Neuro Fuzzy Inference System with Hardware Implemented Real Time Parameter Update ", MACRo 2015- 5th International Conference on Recent Achievements in Mechatronics, Automation, Computer Science and Robotics, pp.211-221.

[6] U.A. Okengwu and E.O.Nwachukwu, (2014), "Formal Specification Of Neuro-Fuzzy System For Optimizing Hospital Distance", International Journal of Information Technology and Business Management, Vol.30 No.1, pp.33-41.

[7] R. Narayanaswamy and N P G Bhavani. (2016), "Hybrid Energy System fed ANFIS based SEPIC Converter for DC/AC Loads", International Conference on Computer Applications 2016, pp. 15-21.

[8] R. Kothandaraman and L. Ponnusamy, (2012), "PSO tuned Adaptive Neuro-fuzzy Controller for Vehicle Suspension Systems", Journal of Advances in Information Technology, Vol 3, No 1 (Feb. 2012), pp.57-63.

[9] R. Cheng and Y. Jin, (2015), " A Social Learning Particle Swarm Optimization Algorithm For Scalable Optimization" , Information Sciences Journal, Volume 291, pp. 43-60.

[10] P.K. Das, H.S. Behera and B.K. Panigrahi, (June 2016), " A Hybridization Of An Improved Particle Swarm Optimization And Gravitational Search Algorithm for Multi-Robot Path Planning", Swarm And Evolutionary Computation, Volume 28, pp. 14-28.

[11] Yuhuai Wang, et.al., (2016), " Improved Particle Swarm Optimization Algorithm for Optimization of Power Communication Network ", International Journal of Grid and Distributed Computing Vol. 9, No. 1, pp.225-236. 
[12] Ch.-Feng Wang and K. Liu, (2016), " A Novel Particle Swarm Optimization Algorithm for Global Optimization ", Computational Intelligence and Neuroscience, Volume 2016 (2016), Article ID 9482073, 9 pages.

[13] Luca Bonsignore, (2014), " Neuro-Fuzzy Fault Detection Method for Photovoltaic Systems", Energy Procedia, Volume 62, 2014, pp. 431-441.

[14] H. Abu-Rub, A. Iqbal, Sk.M. Ahmed, J. Guzinski, M. Adamowicz and M. Rahimian, (2011), "Rotor Broken Bar Diagnostics in Induction Motor Drive using Wavelet Packet transform and ANFIS Classification”, IEEE International Electric Machines \& Drives Conference (IEMDC) , Niagara Fall, Canada, May 15-18, pp. 365-370.

[15] R. Saravanakumar, K. V. Kumar and K.K. Roy, (Sept 2009), "Fuzzy Logic based fault detection in induction machines using Labview", International Journal of Computer Science and Network Security, Vol. 9, No. 9, pp. 226-243.

[16] K. V. Kumar, S. S. Kumar and B. Praveena, (Aug 2010), "Soft Computing Based Fault Diagnosis", International Journal of Computer and Electrical Engineering (IJCEE), Vol: 2, No: 4, pp. 753-760.

[17] M.A. Awadallah, M. M. Morcos, (Dec 2004), “ ANFIS-Based Diagnosis and Location of Stator Interturn Faults in PM Brushless DC Motors", IEEE Trans. On Energy Conv. Vol. 19, No. 4, pp. 795-796.

[18] Nuri Gokmen, et. al., (2013), " An efficient fault diagnosis method for PV systems based on operating voltage-window", Energy Conversion and Management Journal, Volume 73, September 2013, pp. 350-360.

[19] Yihua Hu , (2015), " Online Two-Section PV Array Fault Diagnosis With Optimized Voltage Sensor Locations", IEEE Transactions on Industrial Electronics, Vol. 62, Issue: 11, pp. 7237 - 7246.

[20] Ahmed Houssein, Nicolas Héraud ; Ibrahim Souleiman ; Guillaume Pellet, (2010), "Monitoring and fault diagnosis of photovoltaic panels", Energy Conference and Exhibition (EnergyCon), 2010 IEEE Internationa, pp.389 - 394

[21] Suhail M. Odeh, (2011), " Using an Adaptive Neuro-Fuzzy Inference System (AnFis) Algorithm for Automatic Diagnosis of Skin Cancer ", Journal of Communication and Computer, Vol. 8, pp.751-755 